
Investigations

\title{
Coronavirus Transmission-- Accidental Risks, Facts and Challenges: A Review
}

\section{Upadhyay Ravi Kant}

Department of Zoology, D D U Gorakhpur University, Gorakhpur 273009, India

*Corresponding Author

Received: $2^{\text {nd }}$ June, 2020

Accepted: 22nd June, 2020

Published online: 24th June, 2020

https://doi.org/10.33745/ijzi.2020.v06i01.016

\begin{abstract}
Present review explains different modes of transmission of coronavirus, facts and challenges people have faced at global level. Anthropogenic activities such as trade, transport, travel, business, tourism and religious are responsible for transmission of this virus. It is noticeable that among all modes of transmission human mistakes have increased the severity of disease as super spreaders and unknowingly enhanced the accidental unmanageable risks in high density population zones. Transmission is largely supported by weather conditions such as humidity, temperature, precipitation and industrial pollution in urban areas. It is also seen that housing designs and physical amenities are also responsible for indoor flu virus transmission. Though, it seems very challenging task to mitigate transmission of this deadly virus in near future, but two important ways can cut down virus transmission i.e. by genetic locking or switching off virus spike protein genes in genome. It will stop climate induced genetic variabilities mainly mutations in virus, that may result in zeroing the infectivity and mortality. Second by using advance technology virus invasion on human population can be effectively controlled by applying social distancing, clinical care and proper monitoring of Covid-19 patients. Because development of vaccine against this virus will take more time, hence, all possible therapeutics such as Ayurvedic preparations/medicines and conventional methods should apply for instant control of virus; morbidity and mortality in human population. Fast acting physico-chemical devices which could disinfect thousands of people in a day are to be used for decreasing the infection rate and increasing the sustainability of infected patients. For checking further emergence of viral diseases W.H.O. should take every reason and negligence in its cognizance and intervene in the matter, so that pandemic disasters may not happen in future.
\end{abstract}

Keywords: Coronavirus, Transmission, Genetic switching, Climate induced variants, Vaccine, Covid-19

Citation: Upadhyay R.K.: Coronavirus transmission-- accidental risks, facts and challenges with special reference to India: A review. Intern. J. Zool. Invest. 6 (1): 196-216, 2020. https://doi.org/10.33745/ijzi.2020.v06i01.016 


\section{Introduction}

Covid-19 is more disastrous as it is causing high infectivity and large numbers of deaths that have been reported round the globe (Catrin et al, 2020). It is highly essential to completely wipe out coronavirus from the human society across the world by using all conventional, physical, clinical and therapeutic methods (Kuldeep Dhama et al., 2020). More important is to stop second wave of this highly mutable virus and its complete mitigation must be done as quickly as possible. In last 20 years zoonotic viral diseases have been emerged and caused heavy mortality in human beings (RodriguezMorales et al., 2019; Valdivia-Granda et al., 2020). Two main types of modes of transmission, direct and indirect are more prevalent but virus is also transmitted by food and drinking water supply. Viruses transmit by some vector species and have reservoir host is very easy to control, but human to human transfer occurring in case of coronavirus is very difficult to control (Eunha Shim et al., 2020). It is a very challenging task to control such type of transmission and break the continuing chain in human population/ community. Most of the viruses which are transmitted by certain vectors, if vector population is controlled, both infection and mortality can be controlled very easily. Coronavirus grows in upper respiratory tract and is released in open air through sneezing and coughing by patient. Thousands of micro aerosols or small droplets suspend and virus live for two three hours in air and enter inside next host human body through inhalation of air (Kristin et al., 2020) (Table 1).

Seasonal climatic changes like humidity and temperature enhance the impact of virus. Because ambient humidity present in atmosphere raise the respiratory droplet size and its stability as water content evaporates. Two physical changes occur in sneezed air, first droplet size get increase with down pouring rain drops that quickly come to the ground. Small humidified aerosols remain suspended in air for longer time after evaporation. People on road accidently inhale these influenza virus loaded aerosols with respiratory air. Relative humidity also assists in removal of infectious particles both by increasing the settling of large, water-laden droplets and by hastening virus inactivation. Another environmental factor which largely influences viral transmission is precipitation. First rains though help in washing of suspended air droplets of infectious agents but humidity in soil increases the stability, transportation and natural spread of virus from human spits, faeces, drainages and wastes. Changes in weather or climatic factors other than precipitation affect seasonal infection rates. Areas where no air pollution is available and fouling air is least they remain devoid of any infection. Mainly in open climate of villages and single storey housing pattern and spatial separation of one village to the other decreases virus transmission mainly, but ill habits of smoking, spitting, and tobacco chewing and open drainages provide space and stay to this deadly virus and add risk to transmission (Table 1) (Tang et al., 2020).

In urban areas due to high density of population amount of contagious air increases in air, less wind movements, close air circuits enhance the transmissibility of viruses. If foul smell released from stacked toilets in multistoried buildings due to pipe leakage it mixes in air currents flowing through indoor spaces. It spreads in nearby spaces with the 
Table 1: Different modes of transmission and level of infectivity in population

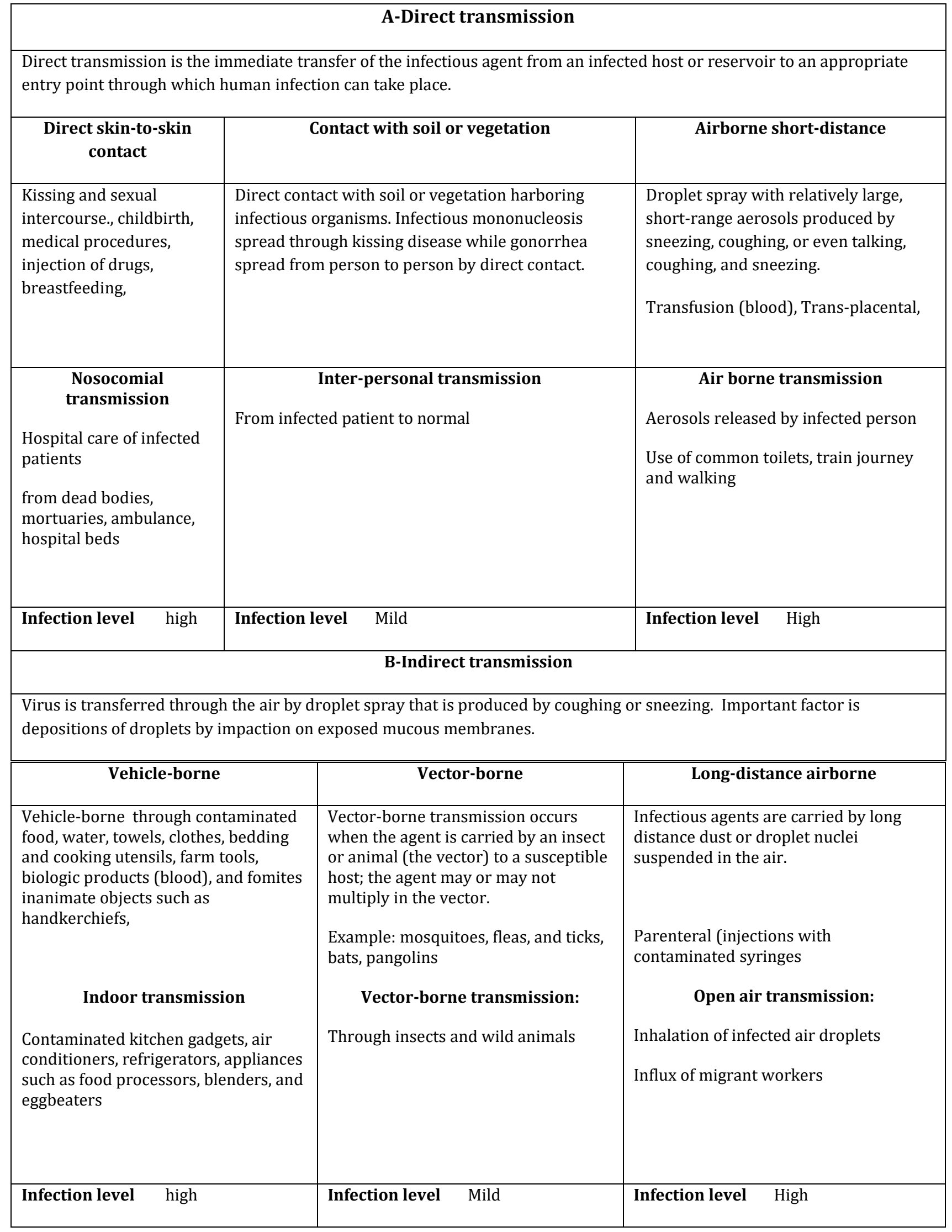


speed of air currents flowing through galleries; if cross ventilation is not available it increases respiratory virus infectivity and transmission. Further, centralized air conditioner facility circulates such air and pumps it in to all air suction through filter system. Virus stays in air conditioner filters for longer time, it is highly dangerous because it increase chances of infection/exposure through artificial ventilation.

In case of airborne RNA viruses, rate of air inflow and outflow, presence of carbon dioxide $\left(\mathrm{CO}_{2}\right)$ content of the air, ventilation temperature and time of stay increases the spectrum of infection. Such inadequate ventilation is quite dangerous as it speedily make passive inhalation of virus particles. This is the main reason that coronavirus has largely targeted such human habitations and caused high infectivity and high mortality. Thus, severe man to man transmission has been observed in close door air circulation systems. This was also happened in aero planes, air condition coaches of trains, buses and hiring taxies and hospitals. This is the main reason that coronavirus infection becomes more common acute illnesses among humans due to close proximity of patient and un-diseased human beings. That is why human mistakes have seriously increased virus transmission, by both direct or indirect routes, and all it happens in disparate regions around the globe (Todd, 2017).

In India in next month meteorological factors will change, both humidity and rains will increase the natural rate of virus infection as well as transmission among individuals. Environmental factors such as relative humidity and temperature can also affect virus survival (Weber and Stilianakis, 2008). The third factor social distancing has been disturbed due to un-locking of cities and towns. With this population inter-mixing in crowded places will increase the passive transmission of this virus, that may prove more fatal. Besides, environmental factors, non-environmental factors such as seasonal changes in behavior, family and social structures may also increase the intensity of virus infection (Koonin, 2020). Alarmingly in three rainy months June, July and August more serious public health implications might be seen in respiratory virus transmissibility and rates of infection. Therefore, un-locking is not in favor of population in India and we have to remain more vigilant in decision making. Even though Covid-19 affected countries impose heavy lockdown, extreme containment and mitigation strategies were applied but it was either delayed or wrongly imposed that is why its incidences were increased out of operational area (Jiumeng Sun et al., 2020). This is the main cause that super-spreaders have spread this disease in highly dense urban population (ValdiviaGranda and Richt, 2020).

\section{Indoor transmission}

Indoor transmission of viruses among family members occurs through use of common kitchen, lavatory and toilets. Most viruses and bacteria that cause cold, flu, and food borne illnesses spread through hand-to-hand or hand-to-food contact (Cliver, 1997; Todd, 2017). Items in the kitchen are contaminated by direct contact with contaminated person, foods, pets, or other environmental sources. Regular cleaning of kitchen usable items with hot water and surfaces before and after their use is highly important. Kitchen usables such as towels, sponges, and scrubbers provide surface for growth of microbes. More important is treatment of openers, cutting 
board, food processors, blenders, and eggbeaters which should be decontaminated with hot water. Sink drains, house drainages, water outlets, safety tanks, contaminated kitchen gadgets should not be used. Both cleaning and disinfection of kitchen, fridges, air conditions, air blowers, fans, clothes and surfaces is quite important (Table 1). Both disinfectants and sanitizers are used for decontamination. Sink used in kitchen can be decontaminated by using hot water. Use soap and warm running water for cleaning of kitchen drains and outlets (Guimera et al., 2005).

Long time use of fridges without its sanitization easily makes transfer of rotten or contaminated food to fresh food. Freezes are store house of food borne illnesses. After cleaning, it should be resurfaced with bleaching solution. Besides this, human food habits are seriously responsible for food borne illness. The main sources of infection are unprocessed food items, open animal meat and sea food, raw meats, poultry and fish are main source of flu viruses. Seafood, particularly oysters, clams, shellfish, and poultry chicken are important source of bacteria and flu viruses. Unpasteurized cheese, contaminated fruits and vegetables also transmit flu virus by hand to hand touch. The easiest transmission is possibly by eating raw seafood or half cooked food mainly cultivated marine shrimps ((Todd, 2017).

\section{Nosocomial transmission}

Nosocomial transmission is an important mode of virus infection such as handling of PPE kits, gloves, medicines, medical appliances, coats, bed sheets, chairs, key rings, dusters, towels, medicines and serum. This hospital acquired infection is an important public health issue. From patient's the infection is easily transferred in care providers, nursing persons, doctors and other hospital inmates by direct contact. It can be controlled by training and sanitation and use of super quality safety equipments but air transmission is not very easy to control. At bigger hospitals this problem can be easily handled by isolating mechanism and developing separate wards in it, but in OPDs this is not very easy to prevent airborne transmission (Garner et al., 1988). It is a great subject whether a medical staff or a doctor always carefully wash hands after observation of serious cases. A single touch on contaminated chairs, tables, doors, panes, curtains and towels and appliances are big source of flu virus infection if not sanitized properly. For virus infected patients single room accommodation with separate ventilation should be provided to accommodate all infected patients (Gao et al., 2020). All respiratory cases must allocate single rooms only. Temporary isolation units can be developed by distancing the patient bed space to protect from airborne transmission. It is true that hospital environment associates with all types of patients i.e. sick, infected and immunocompromised individuals sharing the same building.

Coronavirus is highly mutable virus and can attain both negative and positive mutations according to changing physical climatic factors mainly seasonal variability of temperature, relative humidity, rainfall, wind velocity, day light, altitude and gravity. Among important reasons is genetic susceptibility of virus particle to changing weather conditions. It is a well known fact that ocean is a large natural habitat of thermophilic viruses. 
Coronavirus is thermophilic virus found in yellow shrimp cultivated in marine water in China and used as sea food by many European, Asian, African and Australian countries and has vast trade and supply across the world. Basically marine shrimp is natural host of viruses which is found in ocean basement (Nigro et al., 2017). Transmission of coronavirus is so high that it has spread through air travelling and showed its worldwide presence within 120 days and gripped whole world in its fatal clutches. Virus has been imposing serious public health threat and making heavy economic losses to human society mainly to world economy.

This highly contagious virus is spreading through any route i.e. by direct contact, indirectly by touch, fowling smell, spitting, inhalation of infectious air droplets, due to close contact of clothes and other daily use items (Tang, 2009; Tellier, 2009). Hence, for protection sanitization should be done repetitively by fusion of disinfectants and thermal treatment of air borne aerosols can destroy this virus. Use of $\mathrm{N}-95$ masks, air aspirators, PPE kits, gloves, sanitization of surfaces, hand washing by alcohol based sanitizers and treatment of air filters by using disinfectants and essential oils, and use of UV lights can reduce indoor coronavirus transmission as suggested for other viruses (Noakes and Sleigh, 2009).

\section{Cultural transmission}

Cultural transmission occurs due to human living, attitude, behavior, communication and religious and social activities. Restriction in group activities can lower down the rate of transmission. This is lonely solution available today. Other important factors is housing pattern, food habits, living pattern, sanitation, human behavior regarding waste disposal and community cleaning, and human interaction to animals and pets. Virus transmission depends on size of personal space, air space, behavior and living style in heterogeneous group of people. Both personal distancing and culture habits prohibit flu virus infection. Religious ceremonies, fares, pilgrimages, worships are main contributor of community virus transmission (Peeri et al., 2020).

\section{Architecture or housing design}

Multistory buildings are most common habitation of human society in metropolitan, megapolis and large colonies. For making comfortable, leisure and pleasant life so many factors such as heat, cold, light, air, moisture, dryness and ventilation are kept in mind accordingly (Sturgis Russell, 1989). A housing design with proper sunlight, heating and insulation, and horizontal and vertical air circulation are most important components of architectural program design. One of the important spreader of coronavirus in housing societies is architecture or housing design (Holm, 2006). In such buildings corridors, galleries are too skirted and narrow and social distancing is not possible to maintain. It is a fact and reality that among all the factors orientation of building is highly responsible for spread of coronavirus. First reason is entry gates/ doors of two opposite houses/flats are front to front, if someone is infected in one flat will simultaneously get infection because an easy breach of social distancing. Second major reason is use of lifts. These are main transportation vehicles for vertical human movements mainly upstairs and down stair activities. Coronavirus takes benefit of all these and easily transmit through elevators or lifts. These lifts once get infected with coronavirus are not very easy to disinfect. In 
such societies if a single person makes carelessness this is much enough to infect whole society due to close contact of and exposure to virus in horizontal and vertical circulation air.

The most important and major factor is housing shape, slope of the plot, spatial separation and readability of the development (Sturgis Russell, 1989). Due to shortage of space and making a design perfect real estate developers have started transformation of architectural planning (Nikolas and Jokiniemi, 2008). In beginning these deigns were "I" shaped or single line multistory designs, having east west face, there was no chance of entry of fouling air in houses, these were quite airy and safer. These "I" shape were converted in to "L" shape housing structures, and open volume and garage were expanded and added houses were made one extra arm. In next transformation these were given "H-shape" and open spaces kept same but two unit houses increased the chances of intermixing. In next step housing design changed into " $\mathrm{C}$ " to "U"; " $U$ " to "D" and finally " $O$ " shape houses. Now existing volume of the plot was not increased but number of flats and floors have been multiplied and increased manifold. In all these housing societies toilets and lavatories pass from nearby central place which are pressure pockets of fouling smell, which spreads from draining pipes. All these facilities stacked one over one at each and every floor. Further a major change in " $D$ " and " $O$ " shape seen is that to make front of houses towards outside or out facing fronts have shifted the lavatories and toilets in backside. It was kept similar in all flats, hence, fouling smell always remains in central inner open space, it circulates from ground floor to top floor. This is the main cause of heavy transmission of coronavirus. Other factor in such buildings is narrow corridors, passageways and open lobbies where social distancing is never possible. Further, ill habits like smoking, spiting and open waste baskets are main cause of virus transmission in societies. However, irresponsible behavior and carelessness of a single man can makes society environment more hazardous and keep on hold whole society in risks of virus infection.

\section{Artificial air ventilation systems}

The third major factor is use of centralized air conditioning facilities in cold climates housing societies. In Cold weather/temperature mucin hyper-secretion occurs from human bronchial epithelial cells (Li et al., 2011) that appear as runny nose and a symptom of respiratory infection (Maria D'Amato et al., 2018). Inhalation of cold air affect respiratory surface in lung and assist in flu virus growth and give rise early flu like symptoms (Koskela. 2007). Ventilation is also effected at low and high ambient temperature, especially in artificial system hyperventilation does air surfaces dry, that later on results in irritation and inflammation of respiratory cilliary epithelium (Davis et al., 2011) of lung tissues (Freed and Davis, 1999; Sundell and Levi, 2011). This is the main reason that breathing problems get increased all of a sudden due to cold climate in asthmatics (Millqvist et al., 1987). Inhalation of cold air increases the number of inflammatory cells in the lungs in healthy subjects (Larsson et al., 1998). Coronavirus circulates and re-circulates easily through open spaces wherever it is available and it enters in the filters of air conditioner and remains active for longer periods. Hence, it is advised not to use split AC or centralized 
AC facility till the infection completely disappears.

\section{Food habits and life style}

Most of the viruses are transmitted to humans via food and feeding habit. It depends on presence of contaminants and pathogens in their surroundings from where direct or indirect contamination and to foods or spread though unhygienic conditions/feces or from market places (Dennis Normile, 2020). Viruses transmitted by a fecal-oral route are not strongly dependent on foods as vehicles of transmission, but viruses are important among agents of food borne disease. Other transmission vehicles in damp and wet sides are most often mollusks, flying insects and larvae found in contaminated waters. It is also real fact that many other foods are contaminated directly by handling of food items by the infected person/s. Contamination can be prevented by keeping faeces not to contaminate food or by treating vehicles such as water in order to inactivate virus that might be carried to food in this way. Virus multiply in food, can be inactivated by adequate heating. Other methods of inactivating viruses within a food are relatively unreliable, but viruses in water and on exposed surfaces can be inactivated with ultraviolet light or with strong oxidizing agents (Cliver, 1997). But on porous surfaces virus survives for lesser time than hard surfaces. Metal objects, plastics, synthetic polymers, fruit surfaces and vegetable virus can stay more than $8 \mathrm{~h}$ to days. A reality about newspapers is that during printing, paper passes through high thermal heat and become sterile.

\section{Trade and travelling}

For world wide spread of coronavirus infection international trade, and travelling by flights, ships, trains and surface transports are responsible (Chinazzi et al., 2020). More than $45 \%$ transmission occurred due to business activities. International trade essentially need transportation networking that is maintained through air, sea and land transport networks for ferrying employees, workers, passengers and porting of raw materials and supply of goods (Chinazzi, 2020). With raw material and unsafe handling of products also carry microbial pathogens and their vectors also move further, faster and reach in distant places both cross country and across the continents (Guan et al., 2020). Speedy transportation and air travelling speed up transmission of infectious disease pandemics to far distant countries. Recent coronavirus pandemic has been proliferated within 120 days of its emergence and persisting in more than 207 countries of the world Hence, it is advisable that after seeing potential implications of international air travel, shipping routes and invasion of virus and infectivity and mortality new trade rules be prepared and must be enacted.

International trade routes and arrival of overseas visitors, non-residents and tourist were initial careers of this deadly virus (Rodriguez-Morales et al., 2020). All these human activities carried the virus to new environment. Within no time virus started changing itself according to new climate. These climate induced mutations strengthen the virus and enhanced fatalities and infectivity. It has been reported that attainment of genetic variability or mutations in prevailing climatic conditions also increased the intensity of transmission of influenza virus (McNeil, 1976; Ferguson et al., 2003a). It leads to emergence of new virus strains (McNeil, 1976). Contrary to this, coronavirus at few places causing high 
infectivity but low fatality rate in some countries but its killer strains become very serious health problem in some developed European countries. Its severity also differed from city to city, but nearly similar in metropolis cities. Both genetic regulation of virus behavior by the host body and level of immune defense decide symptomatic appearance. More fatalities occur due to over activation of immune defense mainly cytokine burst in lungs. It is also fact that influenza infection falls every year almost in every country and infect around $20 \%$ of children and $5 \%$ of adults worldwide develop symptomatic influenza each year. But it shows low fatality rates (Nicholson et al., 2003).

Based on reports published influenza viruses mutates very fast. This feature enable them sustained human-to-human transmission (Ungchusak et al., 2005). Behind mutations climatic factors, host immune system and genetics; and antibiotics are broadly responsible. Among all the causes main reason behind uncontrolled transmission is carelessness of human beings; mainly close contact and open air exposure, use of common facilities and unhygienic practices. In addition, lack of real time epidemiological and genetic data, reason of emergence has increased the severity of infection. Covid-19 outbreak has not given enough time to think about its clinical control and make appropriate preparations. Arrangements could not become possible in time as useful medical care equipments, medicines, creation of hospitals and making a responsible authority and disease combating planning was much delayed. This is the main reason that few of developed countries could not manage the infection in time and worst scenario of pandemic impact and severity of infection with large numbers of fatalities are seen. On other side virus attack is also not providing enough time to patients to develop humeral immunity, it is obstructing the germ line defense mainly phagocytic, inflammatory and anatomical barriers. Although it is theoretically possible to create vaccines against any new influenza virus, but it essentially need enough time, large budget and production capacity. Genetic instability of the virus is main escaping effects or failure of newly developed vaccines (McNeil, 1976).

There is possibility that virus may create new problems during months of rainy and winter season. This may happen due to change in climatic regimes and navigation movements, possibly virus may migrate between northern and southern hemispheres to become epidemic in cold-weather seasons as suggested in past by Cox and Suabbarao (2000). A new mutated strain may evoke new pandemic or a silent cross over due to self genetic withdrawal of virus after certain replication cycles, as it is mostly seen in case of SARS and avian influenza virus in South East Asia in the past. If virus mutate sufficiently and acquire changes both transmission rates (Ungchusak et al., 2005), and its lethality will increase (Enserink, 2004). The only remedy that can stop virus exchange is international ban of air travel routes for next six months to protect uninfected population from susceptible global population, otherwise by seeing current rate corona will prove more fatal than present pandemic (Osterholm, 2005a, Osterholm, 2005 b, Oxford, 2005). Therefore, both clinical and physical adequate preventative measures are to be keeping in place to stop trans-continental and cross country transmission of coronavirus. 
For fast control of this highly transmitting virus is to explore its host range. It is also oblivious to find and genetically characterize it's close allies, which might replace this virus with a different kind of disease such as eye flu, swine flu or bird flu. Wuhan shrimp and animal markets are manmade hot spots where hundreds of animal viruses are easily entering into human body. Among other sources of virus are sea food supply, warehousing and its loading in ships at ports. From these places easy "spillover" infections are much possible and virus can get easy entry into human host. It is also larger fact that rarely; viruses gain the ability to spread efficiently within a new host, but first they slowly read conditions of survival and slowly starts their establishment in a previously exposed or susceptible host. Steps involved in transfers of viruses to new hosts include contact between the virus and the host, infection of an initial individual leading to amplification and an outbreak. However, replication of virus and its generation of highly infectious progenies within the original or new host depend on mutations acquired by the viral strain. However, a beginner original virus enter into different hosts and incubate in varied environmental conditions, gain the ability to change slowly and stabilized such changes when pass on to one individual to next one. These transfers involve either increased exposure or the acquisition of variations that allow them to overcome barriers to infection of the new hosts. In these cases, devastating outbreaks can result. Virus very rapidly completes 200 replication cycles in high mode of aggression and causes more fatalities, as soon as it start replicating normally its aggression get slow down and after near about completion of 600 cycles its speed might become stand still. It is possible due to conversion of operative genetic switches into non-operative genetic switches. In last stage hardly infection may visualize in less than hundred of individuals in 10 million populations.

\section{Business}

Long lockdown imposed to curve on infection of coronavirus; business activities were shut down. As many countries are unlocking the markets, hence, it is liability of business owners and controlling authorities that they should protect their employees from virus attack (Koonin, 2020). This is highly essential to screen employees at entry point, abide with them safety rules, sanitation hand washing, and providing them safety kits or its alternatives. Make alternative arrangements and opt alternative ways such as operate online business, take orders and provide supply only after disinfecting hands and proper sanitization. It will keep people away from shops and malls, and reduce chances of close contact. Facilities like video conferencing can keep customers face-to-face for online shopping they can select usable items from home and place an order and make digital payments. Employees can work in alternate shifts and supply and demands can be managed up to $18 \mathrm{~h}$ a day. Update employees with coronavirus infection information, hotspots, social distancing and safety precautions. Business houses also own the responsibility to diagnose their employees by most authentic antibody tests or RT-PCR method (Ostrovskaya et al., 2020). They should train their employees to use liquid soaps, disinfectants, and hand sanitizers for cleaning to protect from coronavirus infection. All those who involve in business must follow guidelines for personal and social safety by following social distancing rules to avoid 
coronavirus infection and its prevention (Peeri et al., 2020).

\section{Facts and challenges}

\section{Why cities become hot spot}

The main cause behind formation of hot spots in cities is disobeying rule and breakage of social distancing. Unknowingly, close contact of persons during purchasing of vegetables from vendors and shopping from kirana stores and food item suppliers spread infection in community people. Other important reason is penetration of NRIs without listing and reporting to local authorities. The chain of infectivity reached to their family members, neighbors, friends, and other people who came into their contact. In cities where population is living in more congested areas people come into contact very easily due to public movement. Breakage of social distancing is seen in buses, trains, vegetable markets, weekly markets, hats, and social and religious rituals proved costly (Omar et al., 2009). The chances of contact transmission occurred in hospitals, petrol pumps, banks, suppliers, and bus and train sheets. Just after unlocking people are not taking social distancing seriously even they know about its consequences. Now no rule has been seen in maintaining physical distancing or social distancing in market places. People show laxity in social distancing and not bearing masks. This lonely item protects from inhalation of flying aerosols in open place, while gloves provide protection from contaminated surfaces. Maintaining of 6 feet distance in market is now become a joke else nothing. This is the main reason that a steep rise in cases has been seen in Mumbai, Chennai, Delhi, Ahmadabad, Thane, Pune, Hyderabad, Kolkata, Indore, Jaipur, Jodhpur,
Chengalpattu and Tiruvallur. These 13 cities will continue to see the restrictions similar to those clamped in containment zones even when the nationwide lockdown ended on May 31.

\section{Unfortunate spread killed thousands}

Initial infection was spread due to serious negligence done by NRIs and religious hubs; they have tried to hide every fact about their exposure to this highly contagious virus from the people of country. It is hard truth that overseas Indians, Jamaaties and tourists are solely responsible for spread of Covid-19 disaster in India. They came into notice when hot spots Covid-19 clusters were emerged, since then a regular increase in cases is going on. Thousands of innocent people have lost their lives; with unaccountable sufferings, pains, hunger and disparity was faced by them on way back to home. How worst was the situation this country has passed through that pregnant ladies, children of age lower than five were seen on route trying to reach their native places thousands of kilometers on foot.

\section{Migrant influx enhanced the transmission rate}

A spike in COVID-19 cases has been seen in last four weeks due to influx of migrant workers in Uttar Pradesh and Bihar from Maharashtra and Gujarat where corona infection is spreading very fast day by day. Both were having more than 37 lakhs of workers which have been shifted from industrial states to their home state in last 28 days time. There are three categories of migrants; first category those who reached on foot; they have joined their families without quarantine, laborers reached by trucks, private vehicles and own vehicles they also have joined their families without any testing. Among them so many were died on route or 
showed symptoms and hospitalized but their number was less. The third category of laborers are from hot spot buffer zones, most of them were tested positive, so many of them reached to their home by chain pulling of trains and have alarmingly increased the tally of active cases in Bihar and U.P. This third category incoming migrant worker is highly infected and responsible for coronavirus spike in recent days. Till date more than 20 lakh migrant workers have been deported from Maharashtra and Gujrat by ferrying 1565 Shramik special trains. From these incoming migrant workers, over 2,650 were test positive in Uttar Pradesh. In Bihar, more than 3,500 people have been infected from Covid19 while 15 people have lost their lives. There is a serious flaw that laborers reached by trucks, private vehicles and own vehicles, they also have joined their families without any testing and quarantine. This is main reason that numbers of infected cases have been spiked in one week time.

Most of the workers in different states have no livelihood means and living on the brink. The main problem is social distancing which is impossible on working sites (Gabriel et al., 2008). Most construction workers often lack even simple safety gears. They have no masks, no hand washing fluids, and no sanitizers. Another big reason of intermixing of infected people is false messages on social media, after which workers/migrants collected in large numbers in railway station premises in badly infected coronavirus states. The migrants who did get on buses were literally stuffed into them and piled onto roofs to reach their home. It is hard fact that few of the states could not handle the situation well and a huge humanitarian crisis emerged all of a sudden as stranded migrant laborers tried to return home. People were hungry without any means of survival and coming bare foot and getting sick and died in unending cry. They have faced all round disappointment and lack of any facility. Though, it is reality that Indian economy is fueled largely by migrant laborers and workers. Present coronavirus crisis pandemic has made extreme problems to livelihood means and country's economy is halted and become uncertain. Changes in population movement make COVID19 spread differently from SARS (Shi et al., 2020).

\section{Lockdown within lockdown proved costly}

Day by day spike of coronavirus infection is rising, and it becomes uncontrolled and seems unmanageable in 3-4 cities today. There is an outcry all round in few cities in hot spot areas that infection has gone out of control. Every day more than 9000-10000 cases are added to total tally of active patients that has been crossed 3.4 lakh mark with approximately 9000 deaths. Recently this tally has been increased as total cases are more than 5.0 lakh and 12,500 deaths. Infected migrant workers shifted from Maharashtra and Gujarat raised the chances of spread of this Covid-19 in rural and suburban areas of Uttar Pradesh, Bihar, Rajasthan, M.P. Jharkhand and West Bengal. Now we have hardly 20 days to control coronavirus transmission before start of rainy season because flu virus infection increases very fast with increase in temperature, humidity and rainfall. Therefore, it is highly essential to completely wipe out coronavirus from the human society by using all conventional, physical, clinical and therapeutic methods. More important is to stop second wave of this highly mutable virus 
and its complete mitigation must be done quickly as possible.

Imposition of lockdown within lockdown proved costly

For primary control of coronavirus infection lockdown is imposed to keep away the uninfected population from an infected coronavirus patient. It needs slow down of population movements and instant check on intermixing of population (Edward et al., 2020), by prohibiting their gathering at crowded places (Shi et al., 2020; Paital et al., 2020). However, keeping in mind WHO guidelines India has announced imposition of lockdown on $25^{\text {th }}$ of March as a precautionary and safety of people. Here, this step taken by the government was correct but method of lockdown followed was quite wrong, because sudden imposition of lockdown held up more than 37 lakhs of migrant workers in their place for more than 45 days. The right time of lockdown was $25^{\text {th }}$ of February; it was delayed by one month. When people found relief in curfew they rushed in large numbers for purchasing and received coronavirus infection from vegetable vendors, suppliers, chowkidars, gatemans and kirana store owners. It is the right time when lockdown is being necessarily required to curve on the disease successfully. There is a much clear advise from expert groups that only way to lower downs the chances of community transmission in rural India. It is highly needful that government should re-impose lockdown to slow the spread of covid-19 finally till its complete disappearance in hot spots (Edward et al., 2020). For quick control of this pandemic with social lockdown, mass testing and medical care of COVID-19 patient should be increased to achieve the recovery rate beyond 75\% (Paital et al., 2020).
Further, chances of its rapid spread has been increased due to unlocking of lockdown and start of public movement due to opening of markets/shops, parks, industries, offices, restaurants, hotels, surface and air transports. This is second grave mistake done by the government; this is real time to impose strict lock down for two more weeks to stop speedy spread of this pandemic in urban, suburban and rural India. Lockdown within lockdown has been proved costly because people were careless and exposed with this contagious virus.

\section{Public and administrative negligence}

Rapid increase in COVID-19 cases is due to use of common public amenities and hospital beds, buses, trains and market places. Today condition is that we do not have required number of ventilators, hospital beds, equipments, and clinical care usable as numbers of cases of coronavirus are increasing very speedily. Carelessness in discharging the general patients without testing and seeking their corona reports delayed, shifting of corona patients in general wards, and providing dead bodies to family members without antibody testing is very serious issue. This serious negligence is responsible for recent surge in coronavirus cases. This is also observed in aero planes, coaches of trains, buses and hiring taxies. More severe man to man transmission has been observed in close door air circulation systems. This is the main reason that coronavirus infection becomes more common acute illnesses among humans due to close proximity of infected asymptomatic patients. That is why human mistakes have seriously increased virus transmission, by both direct and indirect routes, or infection evokes after 
hospitalization of patients. Among most reported cases ward boys, sweepers, nurses, technicians and other clinical staffs, medical doctors, security personals were found infected. Due to their public services they are bound to dutifulness and working without PPE kits, protection wares and unsafe living places increases the severity of infection where infected patient load is very high. This is the reality that health care workers and doctors, and nurses are over exhausted and living under fear and trauma. Even after knowing the reality, hospitals are running in extreme shortage of staff and high quality health care equipments and shortage of medicines. It is hard fact that unlocking will prove costly for the public and economic well being, reasons stakes to add high infectivity and more fatalities may occur in coming months. Government has forced to open lockdown because of heavy economic downturn.

\section{Effect of climate}

Climate play important role in spread and spectrum of infectious diseases (Хiaoxu et al., 2016). Flu viruses mostly appear in October and persist during winter months and its severity increases with hemispheric changes. This seems true that coronavirus infection in China was evoked in early October. The winter plays a major role in transmission of all kinds of respiratory viruses and cases of common cold, cough and lung infection get increased simultaneously. Among all climatic factors temperature, humidity and rain fall increase the chances of spread of viral disease. All of a sudden slow growing virus started multiplying very rapidly, infection resulting in enormous morbidity and finally numbers of deaths has been increased and take the shape of epidemics (Mayr, 1990). These epidemics could be controlled only by real time surveillance and assessment of epidemiological data, making prophylactic measures and long term disease combating plans (Chan et al., 1999; Monami et al., 2020). The weather is one of the important factors that triggered the spread of Covid-19 (Tosepua et al., 2020). The vulnerable weather parameters will help classify the risky geographic areas in different countries. Especially, with further reporting of new cases in India, prediction of states with high risk of weather based spread will be apparent (Gupta et al, 2020). Alterations in temperature and absolute humidity range make conditions more vulnerable and enhance pneumonia infection and deaths (Bull, 1980).

Breathing cold air triggers severe bronchoconstriction in asthmatics (ShturmanEllstein et al., 1978). Both upper and lower airways chocked and asthma patient tries a forceful breathing or heavy obstruction occurs that essentially needs tranquilizer, oxygen aspirator lastly a ventilator (ShturmanEllstein et al., 1978; Van Gerven et al., 2012). In cold due to flu virus infection both upper and lower airways show high sensitivity and lung function obstructions. Cold dry air increases nasal responsiveness in flu virus generated allergy (Bousquet et al., 2001). Cold weather spells as a characteristic feature of changing climate will need to be considered in assessing the risk for asthma, especially since heterogeneous human populations may adapt differently to them (Cruz et al., 2007).

Super blooming is possible in rainy season In India transmission of coronavirus is occurring due to direct contact or indirectly by aerosols released in air by corona patient. 
In rainy season, water droplets provide stability to virus in air. In extreme humidity sneezed droplets mixed in air and suspended for longer time and virus remain active for 12 $20 \mathrm{hrs}$. When these air droplets are inhaled unknowingly by a normal person or a susceptible host, starts infection. Virus transmission is affected by ambient humidity, which affects not only the virus' stability but also respiratory droplet size, as water content evaporates. Though, heavy rainfall quickly settles air suspend virus on to the ground but rain water collection in drainages, ponds, tanks and house roof increase the stay time of virus. Through drinking and bathing water it can infect normal person/s. Furthermore, virus remains live for more time in sputum, phlegm, stool and urine of Covid-19 patients. Now hardly we have not enough time to control coronavirus before start of rainy season.

\section{Safety and preventive measures}

Migrants from cities and symptomatic corona patients should keep in isolation centers or special Covid hospitals. They should pass through strict quarantine rules and treatment procedures; all interacting cases must be identified and quarantined. Once the patients are identified, the hospitals must immediately isolate these patients and use contact tracing to identify other potential patients. Compulsory quarantine for all incoming travelers and introducing stiff penalties for businesses and individuals caught contravening safe distancing rules in all public spaces. Both their interaction during 27 days and movements must be kept under close watching. In red and orange zone areas people must keep patience and stay at home and maintain social distancing. For keeping them under communication phone calls and videos, glass separators can be used according to intensity to ascertain physical distancing. Bluetooth application can be used to enable more efficient contact tracing. All such measures could check daily number of unlinked domestic transmission cases. Overseas travelers/residents are strictly stayed for 14-day. They should provide "Stay Home Notice" and placed on outside of home as quarantine. Such patients can be monitored daily via their smart phones using a mix of GPS tracking, video and voice calls. These can also receive daily directions through digital consulting, it prevents person-to-person contamination. At home treatment provide space to more severe patients in hospitals and effective to prevent, identify, manage and monitor Covid-19 affected patients and can minimize the contagion in the society.

\section{Prophylactic and therapeutic measures}

Social distancing is best safety measure to cut down virus transmission at public places and inside houses and industries. But it seems impossible in slums because of very narrow passageways (Abdullah et al, 2007; Corburn et al., 2020). It has been seen that in very small size room or chowl or polythene and tin shade hut more than ten people are residing and they desirably cannot follow social distancing rule. Quarantine centers must strictly keep the infected people under social distancing. Fool proof safety kits, sanitizers, masks, gloves and other accessories also provide safety from infection. These also assist in prevention of nosocomial transmission among non-infected hospital staff and care takers. It is more advisable that social distancing is only a preventive method to avoid infection, but for treatment of virus infected patients fast acting therapeutic methods are to be required. Hence, all possible therapeutic methods such 
as plasma and antibody therapy, anti-viral drugs, molecular and genetic medicines, plant natural products, homeopathic, Ayurvedic, Unani, Shiddha, alternative and complementary medicines and conventional methods should apply for instant control of virus generated morbidity and mortality (Fig. 1). Fast acting physico-chemical devices which could disinfect thousands of people in a day are to be explored for decreasing the infection rate and increasing the sustainability of infected patients. The best way is use of conventional methods such as use of herbal quaths, concoctions and herbal karha, white alum (Harm et al., 2018), honey, and Ayurvedic bhasma. All these are immunity boosting medicinal systems which can be used for control of coronavirus infection (Fig. 2).

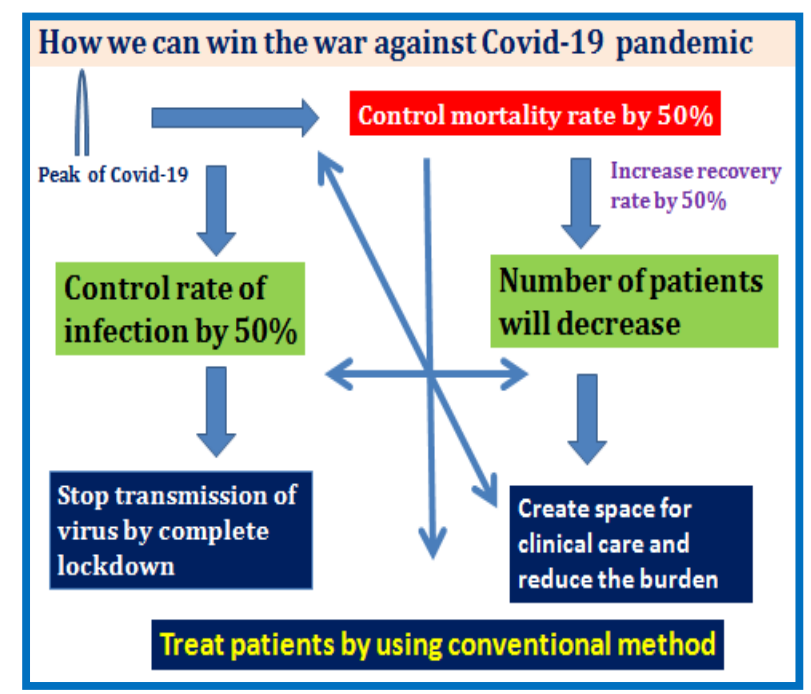

Figure 1: Plan for instant control of coronavirus infection by using conventional methods

Inhalation of hot steam distillate and gargles help to reduce virus load (Hayashi et al., 1995) while thermal inactivation of coronavirus is also possible by using hot $1.5 \%$ salt water or by direct thermal heat (Lauffer and Scott, 1946; De Flora and Badolati, 1973) as it is generated in thermal-aroma-carbon therapy (Upadhyay, 2020).

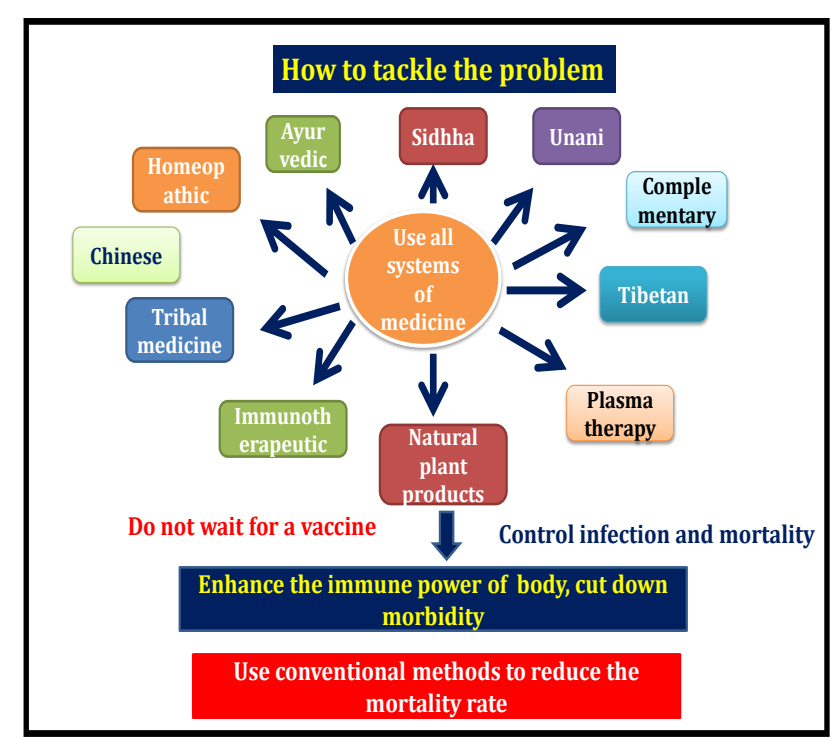

Figure 2: Immunity boosting medicinal systems can be used for control of coronavirus infection

\section{How to tackle the problem}

No concrete therapeutic method and medicine has been prepared so far against coronavirus. It is hard fact that transmission can slow down coronavirus infection rate but better therapeutic can increase the recovery rate beyond $80 \%$. The only way is to treat the patients by using conventional therapeutic methods, it is cheaper, safe and less man power is used. However, this is much advisable that government should declare all conventional methods for treatment of mass number of patients. All different Ayurvedic preparations in Ayush ministry should be known to public and essentially provide to all age groups near hot spots and buffer zones to boost up their immunity to stop deaths instantly. This is time when it is hard to diagnose large number of population because cases are increasing alarmingly. The main problem is unlocking of lockdown and opening of all public places, imagine if any super spreader unknowingly visit the 


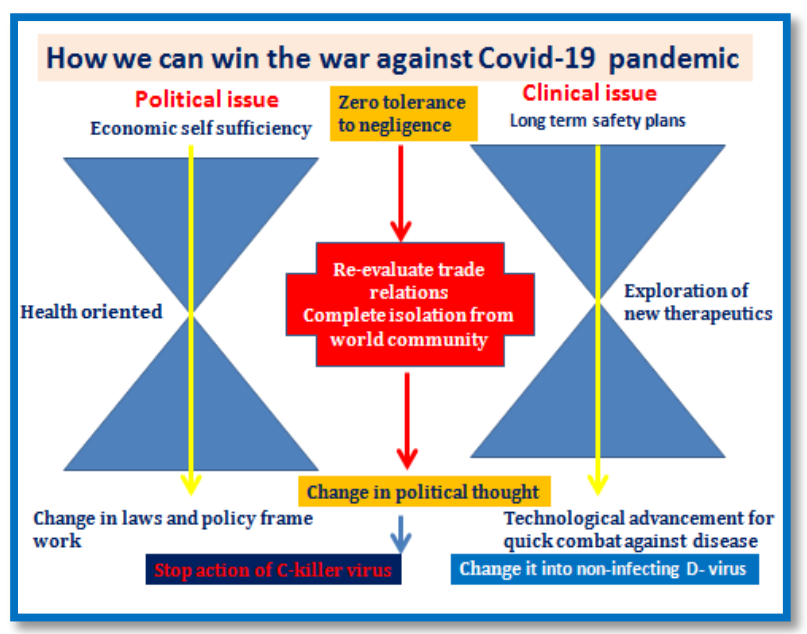

Figure 3: Strategic action plans for controlling the emergence of new virus infection in future

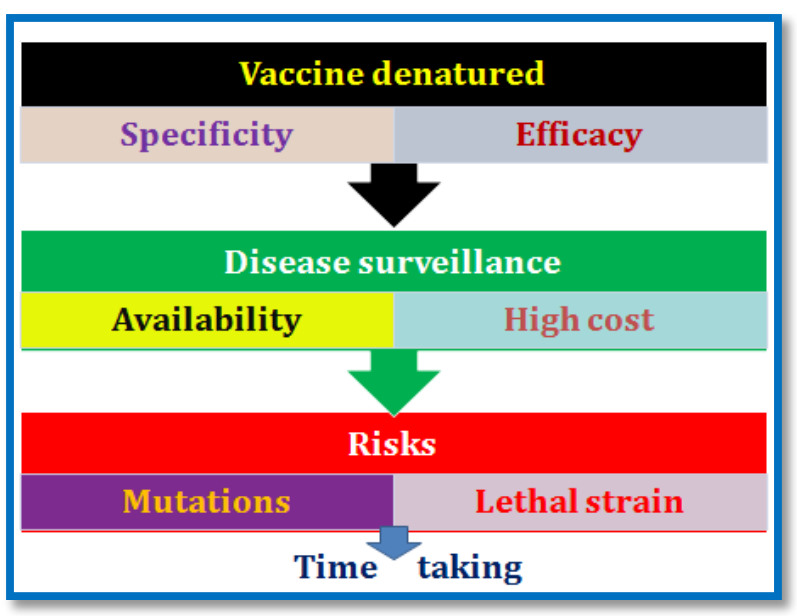

Figure 4: Important attributes of a successful vaccine against coronavirus

crowded public places, what will happen. Although many research laboratories are working for developing an appropriate vaccine against coronavirus but it is time taking, need huge economic resources with a speedy production capacity (Cynthia Liu et al., 2020). There must be a long term strategic action plan for controlling the emergence of new virus infection in future (Fig. 3). But it's easy availability and efficacy is still doubtful because virus is highly mutating and changes its regulatory genes according to chemical, physical and biological environment (Fig. 4). An unknown fear is how long we will remain safe under umbrella of a vaccine and its immunization. Perhaps, coronavirus may acquire new changes in its genome that may result in failure of vaccine that may increase fatality rate. The main danger is reverse transformation of a denatured vaccine strain into virus strain; it will pose a toughest challenge. There is another hope i.e. development of natural resistance by generation of antibodies within body against this virus in exposed persons. But for generation of natural protection or heard immunity against coronavirus approximately $60 \%$ of population is exposed to this virus.

\section{Conclusion}

For instant regulation WHO and world sovereign nations should think positively to revise trade and air traffic rules and laws (Rahimi et al., 2020). This disastrous pandemic must be tackled as a political issue rather than a clinical issue. Because world leadership should think that China is solely responsible for origin and spread of this virus round the globe. China knowingly delayed disclosure of epidemiological information and reality about dreadfulness of coronavirus in time to the world community. This noncooperation and ghastly act of China has not given sufficient time to the world community for enough preparations to fight against Covid-19. This laxity made by Chinese communist government has thrown much enlarged humanity in burning furnace and heavy costs have been paid by millions of innocent deaths occurred round the globe. Even China has tried very cleverly to make every effort to convert pandemic into an economic opportunity. In this pandemic China has supplied substandard corona testing kits, unsafe masks and PPE kits to several countries. This is real time when all G-7 countries and developing countries should 
forge trade and business and diplomatic relationships with China and isolate it from world community. In this hard step the cries, tears and painful voice of dying people will play a decisive role. This paramount decision will become a peaceful homage to the grieved souls which have been passed away untimely. This is not simple as man is dyeing; it is humanity which is facing perishing fatal consequences and torture.

For instant regulation and quick control of emergence of viral diseases from China WHO should take every reason/negligence in its contingence and heavily intervene in the matter, so that future pandemic disasters may not happen in future. All trade and traffic norms, rules and federal laws must be revised. Nations which follow new international rules should only allow participation in business and cultural relationships, those who do not come in support they must be boycotted from world trade, travel and international relationships. At any level carelessness and negligence related to epidemiological information should not forgive and spare easily. Further, to strengthen fight against coronavirus emergency worldwide funds, medical aids, services, information sharing, institutional researches and technological advancements and new federal rules are needed. Those who are coming from other states should be registered and put inside quarantine centers with strict rules.

\section{References}

Abdullah Brooks W, Terebuh P, Bridges C, Klimov A, Goswami D, Sharmeen AT, Azim T, Erdman D., Hall H and Luby S. (2007) Influenza A and B infection in children in urban slum, Bangladesh. Emerg. Infect Dis. 13:1507-1508.

Bousquet J, van Cauwenberge P and Khaltaev N. (2001) Aria Workshop Group, World Health Organization.
Allergic rhinitis and its impact on asthma. J. Allergy Clin. Immunol. 108: S147-334.

Bull G. (1980) The weather and deaths from pneumonia. Lancet 315: 1405-1408.

Catrin Sohrabi, Zaid Alsafi, Niamh O'Neill, Mehdi Khan, Ahmed Kerwan, Ahmed Al-Jabir, Christos I and Riaz A. (2020) World Health Organization declares global emergency: A review of the 2019 novel coronavirus (COVID-19). Int. J. Surg. 76: 71-76.

Chan NY, Ebi KL, Smith F, Wilson TF and Smith AE. (1999) An integrated assessment framework for climate change and infectious diseases. Environmental Health Perspectives 107: 329-337.

Chinazzi Matteo, Jessica T. Davis, Marco Ajelli, Corrado Gioannini, Maria Litvinova, Stefano Merler, Ana Pastore y Piontti, Kunpeng Mu, Luca Rossi, Kaiyuan Sun, Cécile Viboud, Xinyue Xiong, Hongjie Yu, M. Elizabeth Halloran, Ira M. Longini Jr. and Alessandro V. (2020) The effect of travel restrictions on the spread of the 2019 novel coronavirus (COVID-19) outbreak. Science 368: 395-400.

Cliver DO. (1997) Virus transmission via food. World Health Stat Q. 50(1-2):90-101.

Cox NJ and Subbarao K. (2000) Global epidemiology of influenza: past and present. Annual Rev. Med. 51: 407-421.

Cruz AA, Popov T, Pawankar R, Annesi-Maesano I, Fokkens W, Kemp J, Ohta K, Price D and Bousquet J. (2007) Common characteristics of upper and lower airways in rhinitis and asthma: ARIA update, in collaboration with GA²LEN. Allergy 62:1-41.

Cynthia Liu, Qiongqiong Zhou, Yingzhu Li, Linda V. Garner, Steve P. Watkins, Linda J. Carter, Jeffrey Smoot, Anne C. Gregg, Angela D. Daniels, Susan Jervey and Dana A. (2020) Research and development on therapeutic agents and vaccines for COVID-19 and related Human coronavirus diseases. ACS Cent. Sci. 6: 315-331.

Davies N and Erkki J. (2008) "Construction" def. 15. Dictionary of architecture and building construction. Amsterdam: Elsevier/Architectural Press,. 93. Print.

Davis BK, Wen H and Ting JP. (2011) The inflammasome NLRs in immunity, inflammation, and associated diseases. Annu. Rev. Immunol. 29:707-735.

De Flora S and Badolati G. (1973) Thermal inactivation of untreated and $\gamma$-irradiated A2-Aichi-2-68 influenza virus. J. Gen. Virol. 20: 261-265.

Dennis N. (2020) Novel human virus? Pneumonia cases linked to seafood market in China stir concern. sleepingpanda/shutterstock.com, 10: 35. 
Edward RM and John IPA. (2020) Should governments continue lockdown to slow the spread of covid-19? BMJ . 369 : m1924. doi: 10.1136/bmj.m1924.

Enserink M. (2004) Looking the pandemic in the eye. Science 306: 392-394.

Eunha Shim, Amna Tariq, Wongyeong Choi, Yiseul Lee, and Gerardo C. (2020) Transmission potential and severity of COVID-19 in South Korea. Int. J. Infect. Dis. doi: 10.1016/j.ijid.2020.03.031

Ferguson NM, Donnelly CA and Anderson RM. (2001) The foot and mouth epidemic in Great Britain: pattern of spread and impact of interventions. Science 292:1150-1160.

Ferguson NM, Galvani AP and Bush RM. (2003) Ecological and immunological determinants of influenza evolution. Nature 422: 428-433.

Ferguson NM, Keeling MJ, Edmunds WJ, Gani R, Grenfell BT, Anderson RM and, Leach S. (2003) Planning for smallpox outbreaks. Nature 425:681-685.

Freed AN and Davis MS. (1999) Hyperventilation with dry air increases airway surface fluid osmolality in canine peripheral airways. Am. J. Respir. Crit. Care Med. 159:1101-1107.

Gabriel C and Pellerin H. (2008) Governing International Labour Migration: Current. Issues, Challenges and Dilemmas. Routledge/RIPE Studies in Global Political Economy, ed. I.B. Jacqueline Best, Paul Langley, Anna Leander. Routledge: Oxon.

Gao Chang, Wang Yeming, Gu Xiaoying, Shen Xinghua, Zhou, Daming, Zhou Shujun, Huang Jian-an, Cao B and Guo Q. (2020). Association between cardiac injury and mortality in hospitalized patients infected with avian influenza A (H7N9) virus. Crit. Care Med. 48: 451-458.

Garner JS, Jarvis WR, Emori TG, Horan TC and Hughes JM. (1988) CDC definitions for nosocomial infections, Am. J. Infect. Control 16: 128-40.

Grogan P and Proscio T. (2000) Comeback Cities: A Blueprint for Urban Neighborhood Revival,. ISBN 08133-3952-9.

Guan D, Daoping W, Stephane H, Steven JD, Jingwen H, Shuping Li, Yangchun B, Tianyang Lei, Qianyu X, D’Maris C, Danyang C, Peipei C, Xi L, Bing Xu, Xiaosheng Lu, Shouyang $\mathrm{W}$, Klaus $\mathrm{H}$ and Peng Gong (2020). Global supply-chain effects of COVID19 control measures. Nat. Hum. Behav. 4: 577-587. doi: 10.1038/s41562-020-0896-8.

Guimera R, Mossa S, Turtschi A and Amaral L. (2005) The worldwide air transportation network: anomalous centrality, community structure, and cities' global roles. Proc. National Acad. Sci. USA. 102: 7794-7799.

Gupta Sonal, Singh GR and Chanda A. (2020) Effect of weather on COVID-19 spread in the US: A prediction model for India in 2020. Sci. Total Environ. 728 138860. doi.org/10.1016/j.scitotenv.2020.138860.

Harm H, Derek TO and Christopher BF. (2018) Optimizing the utilization of aluminum adjuvants in vaccines: you might just get what you want. Vaccines 3: 51 .

Hayashi K, Kamiya M and Hayashi T. (1995) Virucidal effects of the steam distillate from Houttuynia cordata and its components on HSV1, influenza virus, and HIV. Planta Med. 61:237-41.

Holm I. (2006) Ideas and beliefs in architecture and industrial design: How attitudes, orientations, and underlying assumptions shape the built environment. Oslo School of Architecture and Design. ISBN 82-547-0174-1.

Jiumeng Sun, Wan-Ting He, Lifang Wang, Alexander Lai, Xiang Ji, Xiaofeng Zhai, Gairu Li, Marc A. Suchard, Jin Tian, Jiyong Zhou, Michael Veit and Shuo S. (2020) COVID-19: Epidemiology, evolution, and crossdisciplinary perspectives. Trends Mol. Med. doi: 10.1016/j.molmed.2020.02.008.

Koonin LM. (2020) Novel coronavirus disease (COVID19) outbreak: Now is the time to refresh pandemic plans. J. Bus. Contin. Emer. Plan. 13:1-15.

Koskela HO. (2007) Cold air-provoked respiratory symptoms: the mechanism and management. Int. J. Circumpolar Health. 66:91-100.

Kristin T, Silke B, Ekkehard S, Lothar HW and Walter H. (2020) Influenza-associated pneumonia as reference to assess seriousness of coronavirus disease (COVID-19). Euro. Surveill. 25: 2000258. doi: 10.2807/1560-7917.ES.2020.25.11.2000258.

Kuldeep D, Khan S, Tiwari R, Maryam D, Malik YS, Singh KP, Wanpen C. (2020) COVID-19, an emerging coronavirus infection: advances and prospects in designing and developing vaccines, immunetherapeutics, and therapeutics. Human Vaccines Immunotherap. DOI:10.1080/21645515.2020. 1735227.

Larsson K, Tornling G, Gavhed D, Müller-Suur C and Palmberg L. (1998) Inhalation of cold air increases the number of inflammatory cells in the lungs in healthy subjects. EurRespirJ. 12: 825-830.

Lauffer MA and Scott EM. (1946) Thermal destruction of influenza A virus hemagglutinin: The effect of $\mathrm{pH}$. Arch. Biochem. 9:75-80. 
Li M, Yang G, Kolosov VP, Perelman JM and Zhou XD. (2011) Cold temperature induced mucin hypersecretion from normal human bronchial epithelial cells in vitro through a transient receptor potential melastatin 8 (TRPM8) mediated mechanism. J. Allergy Clin. Immunol. 128: 626-634.

Li YC, Bai WZ and Hashikawa T. (2020) The neuroinvasive potential of SARS-CoV2 may be at least partially responsible for the respiratory failure of COVID-19 patients. J. Med. Virol. doi: 10.1002/jmv.25728.

Maria D'Amato, Antonio M, Giovanna C, Lorenzo C, Isabella Annesi-Maesano and D'Amato G. (2018) The impact of cold on the respiratory tract and its consequences to respiratory health. Clin. Transl. Allergy 8: 20.

Mayr A. (1990) Environment and occurrence of epidemics; Z. Hyg Umweltmed. 190:1-12..

McLane ML, Nelson JA, Lenner KA, Hejal R, Kotaru C, Skowronski M, Corono A, Lane E and McFadden ER Jr. (2000) Integrated response of the upper and lower respiratory tract of asthmatic subjects to frigid air. J. Appl. Physiol. 88:1043-1050. doi:10.1152/jappl.2000.88.3.1043

McNeill WH. (1976) Anchor Press, New York: Plagues and People.

Millqvist E, Bengtsson U and Bake B. (1987) Occurrence of breathing problems induced by cold climate in asthmatics-a questionnaire survey. EurRespirJ. 71:444-449.

Monami M, Silverii A and Mannucci E. (2020) Potential impact of climate on novel coronavirus (COVID-19) epidemic. J. Occup. Environ. Med. doi: 10.1097/JOM.0000000000001885.

Nicholson KG and Wood JM. (2003) Zambon M. Influenza. Lancet 362:1733-1745.

Nigro OD, Jungbluth SP, Lin HT, Hsieh CC, Miranda JA, Schvarcz CR, Rappé MS and Steward GF. (2017) Viruses in the oceanic basement. mBio. 8(2). e02129-16. doi: 10.1128/mBio.02129-16.

Noakes CJ and Sleigh PA. (2009) Mathematical models for assessing the role of airflow on the risk of airborne infection in hospital wards. J. R. Soc. Interface 6: S791-S800 .

Omar SR and Afifi RM. (2013) A mass gathering experience at the 2009 pilgrimage in Makkah, Saudi Arabia, during the 2009 novel influenza A (H1N1) pandemic. J. Am. Sci. 9: 563-571.

Osterholm MT. (2005). A weapon the world needs. Nature 435:417-418.
Osterholm MT. (2005) Preparing for the next pandemic. New England J. Med. 352:1839-1842.

Ostrovskaya OV, Kholodok GN, Ivakhnishina NM, Morozova NV, Karavyanskaya TN, Golubeva EM, Reznik VI, Savosina LV, Lebedeva LA, Prisyazhnyuk EN and Kozlov VK. (2015) Monitoring of influenza and other respiratory diseases causative agents in children, hospitalized with community-acquired pneumonia in 2012-2013 epidemic season. Zh Mikrobiol. Epidemiol. Immunobiol. 2: 59-65.

Oxford J. (2004) The great influenza: the epic story of the 1918 pandemic. Nature 429:345-346.

Paital B, Das K and Parida SK. (2020) Inter nation social lockdown versus medical care against COVID-19, a mild environmental insight with special reference to India. Sci. Total Environ. 728:138914. doi.org/10.1016/j.scitotenv.2020.138914

Palese P. (2004) Influenza: old and new threats. Nature Medicine 10: 582-587.

Peeri NC, Shrestha N, Rahman MS, Zaki R, Tan Z, Bibi S, Baghbanzadeh M, Aghamohammadi N, Zhang W and Haque U. (2020) The SARS, MERS and novel coronavirus (COVID-19) epidemics, the newest and biggest global health threats: what lessons have we learned? Int. J. Epidemiol. 2020 doi: 10.1093/ije/dyaa033.

Perlman S and Netland J. (2009) Coronaviruses postSARS: update on replication and pathogenesis. Nat. Rev. Microbiol. 7: 439-450.

Piątkowska E and Rusiecka-Ziółkowska J. (2016) Influence of essential oils on infectious agents. Adv. Clin. Exp. Med. 25:989-995.

Rahimi F and Talebi Bezmin Abadi A. (2020) Tackling the COVID-19 pandemic. Arch. Med. Res. 51: 468470.

Ramadhan T, Joko G, Devi S, Effendyc, La Ode Ali Imran Ahmad D, Hariati L, Hartati B, Pitrah A. (2020) Correlation between weather and Covid-19 pandemic in Jakarta, Indonesia. Sci. Total Environ. 725 :138436. doi:10.1016/j.scitotenv.2020.138436.

Rodriguez-Morales AJ, Bonilla-Aldana DK, BalbinRamon GJ, PanizMondolfi A, Rabaan A, Sah R, Pagliano P and Esposito S. (2020) History is repeating itself, a probable zoonotic spillover as a cause of an epidemic: the case of 2019 novel coronavirus. Infez. Med. 28: 3-5.

Rodriguez-Morales AJ, MacGregor K, Kanagarajah S, Patel D and Schlagenhauf P. (2020) Going global: travel and the 2019 novel coronavirus. Travel Med. Infect. Dis. 33:101578. doi.org/10.1016/j.tmaid.2020.101578. 
Sasmita Poudel Adhikari, Sha Meng, Yu-Ju Wu, Yu-Ping Mao, Rui-Xue Y, Qing-Zhi W, Chang S, Sean S, Scott R, Hein R and Huan Z. (2020) Epidemiology, causes, clinical manifestation and diagnosis, prevention and control of coronavirus disease (COVID-19) during the early outbreak period: a scoping review. Infectious Diseases Poverty 9: 29.

Shi Q Dorling D, Cao G and Liu T. (2020) Changes in population movement make COVID19 spread differently from SARS. Soc. Sci. Med. 255:113036. doi: 10.1016/j.socscimed.2020.113036

Shturman-Ellstein R, Zeballos RJ, Buckley JM and Souhrada JF. (1978) The beneficial effect of nasal breathing on exercise-induced bronchoconstriction. Am. Rev. Respir. Dis. 118: 65-73.

Southern A. (2006) Modern-day transport planners need to be both technically proficient and politically astute, Local Transport Today, no. 448, 27 July 2006.

Sturgis R. (1989) "Construction def. B. and "Building" def. A. Sturgis' illustrated dictionary of architecture and building: an unabridged reprint of the 1901-2 edition. Mineola, N.Y.: Dover.

Sundell J and Levi H. (2011) Ventilation rates and health: multidisciplinary review of the scientific literature. Indoor Air. 21:442-53.

Tang B, Bragazzi NL, Li Q, Tang S, Xiao Y and Wu J. (2020) An updated estimation of the risk of transmission of the novel coronavirus (2019-nCov). Infect. Dis. Model 5: 248-255.

Tang JL and Griffiths S. (2009) Review paper: epidemiology, evidence-based medicine, and public health. Asia Pac. J. Public Health 21:244-251.

Tang JW, Lai FY, Nymadawa P, Deng YM, Ratnamohan M, Petric M, Loh TP, Tee NW, Dwyer DE and Barr IG. (2010) Comparison of the incidence of influenza in relation to climate factors during 2000-2007 in five countries. J. Med. Virol. 82:1958-1965.

Tatem AJ, Rogers DJ and Hay SI. (2006) Global transport networks and infectious disease spread. Adv. Parasitol. 62: 293-343. doi: 10.1016/S0065308X(05)62009-X
Tellier R. (2006) Review of aerosol transmission of influenza A virus. Emerg. Infect. Dis. 12: 16571662.

Todd ECD. ((2017) Foodborne disease and food control in the Gulf States. Food Control 73: 341-366. doi: 10.1016/j.foodcont.2016.08.024.

Ungchusak K, Auewarakul P, Dowell SF, Kitphati R, Auwanit W and Puthavathana P. (2005) Probable person-to-person transmission of avian influenza A (H5N1). New England J. Med. 352: 333-340

Upadhyay RK. (2020) Thermal-aroma-organic-carbonfusion therapy: An open air conventional method for clearance of nasal air passage, trachea, lungs and immunity boosting against Influenza Virus. Intern. J. Zool. Invest. 6: 71-93.

Valdivia-Granda WA and Richt JA. (2020) What we need to consider during and after the SARS-CoV2 pandemic. Vector Borne Zoonotic Dis. doi: 10.1089/vbz.2020.2652.

Van Gerven L, Boeckxstaens G, Jorissen M, Fokkens W and Hellings PW (2012) Short-time cold dry air exposure: a useful diagnostic tool for nasal hyperresponsiveness. Laryngoscope 122: 2615-2620.

Weber Thomas P. and Nikolaos IS. (2008) Inactivation of influenza $A$ viruses in the environment and modes of transmission: A critical review. J. Infect. 57: 361-373.

Weber TP and Stilianakis NIA. (2008) Note on the inactivation of influenza A viruses by solar radiation, Relative humidity and temperature. Photochem. Photobiol. 84:1601-1602.

Wickramage K, Peiris S and Agampodi SB. (2013) “Don't forget the migrants": exploring preparedness and response strategies to combat the potential spread of MERS-CoV virus through migrant workers in Sri Lanka. doi:http://f1000r.es/1hsF1000Research 210.12688/ f1000research.2-163.v1.

Xiaoxu Wu, Yongmei L, Sen Z, Lifan C and Bing X. (2016) Impact of climate change on human infectious diseases: Empirical evidence and human adaptation. Environ. International 86: 14-23. 